\title{
Correction to: Nurturing Personal Purpose at Work
}

\author{
Carlos Rey, Juan Almandoz, and Alex Montaner
}

Correction to:

Chapter 8 in: C. Rey et al. (eds.),

Purpose-driven Organizations,

https://doi.org/10.1007/978-3-030-17674-7_8

The original version of this chapter has been revised and correction in the word "authenticity" have been incorporated in figure 8.2

The correction was the spelling mistake in the word "authenticity" mentioned in the figure 8.2 